\title{
Colonic epithelium is diffusely abnormal in ulcerative colitis and colorectal cancer
}

\author{
P Gibson, O Rosella, R Nov, G Young
}

\begin{abstract}
The hypothesis that the colonic epithelium is diffusely abnormal in ulcerative colitis was examined by comparing disease related responses in expression of markers of differentiation by colonic crypt cells to culture with and without butyrate. Cells were isolated from patients with normal colon (15), cancer (24), ulcerative colitis (19), or Crohn's disease (16). Alkaline phosphatase activities were measured in cell homogenates and the rate of glycoprotein synthesis assessed at the end of 24 hours of culture and expressed relative to the rate of protein synthesis as the G:P ratio. Alkaline phosphatase activities, but not G:P ratios, differed across the groups before and after 24 hour culture $(p<0.05)$, activities being lowest in the cancer group and highest in inflammatory bowel disease groups. Butyrate (1 $\mathrm{mM}$ ) suppressed alkaline phosphatase activities in the cancer group by mean (SEM) of $17(4)(p=0.006)$ compared with no change in the other groups. Butyrate suppressed G:P ratios only in the cancer $(6(3) \%, p=0.03)$ and ulcerative colitis groups $(5(3) \%, p=0 \cdot 04)$ and the changes in both were different $(p<0.05)$ from those in normal cells (increase of 10 $(7) \%)$. Changes in ulcerative colitis were different from those in Crohn's disease $(p=0.029)$. Responses were independent of the presence or absence of mucosal inflammation. These data confirm the diffuse nature of epithelial abnormalities in colorectal cancer. In ulcerative colitis, a different pattern of abnormality occurs, supporting the notion that the epithelium is also diffusely abnormal independent of mucosal inflammation.
\end{abstract}

(Gut 1995; 36: 857-863)

Keywords: ulcerative colitis, colorectal cancer, colonic epithelium, butyrate.

University of

Melbourne,

Department of

Medicine, The Royal

Melbourne Hospital,

Victoria, Australia

P Gibson

O Rosella

R Nov

G Young

Correspondence to:

Dr P Gibson, University of

Melbourne, Department of

Medicine, The Royal

Melbourne Hospital

Victoria, Australia 3050.

Accepted for publication

11 October 1994
A series of focal genetic events seem to lead to the development of neoplastic lesions in large bowel epithelium. ${ }^{12}$ Large bowels affected by neoplasia are also characterised by diffuse changes in the epithelium distant from the tumour. These abnormalities have included increased rates of epithelial proliferation and turnover, ${ }^{2-6}$ subtle abnormalities of morphology, ${ }^{78}$ and abnormal expression of markers of differentiation. ${ }^{9}$ Proliferative changes have been directly implicated in the tumorigenic pathway but the significance to tumorigenesis of a change in the biology of differentiating cells is not known. If the mechanisms by which cells develop the abnormalities were defined, then the mechanisms underlying enhanced susceptibility to tumorigenesis might be better understood.

Ulcerative colitis is associated with an enhanced risk of colorectal cancer and some evidence has suggested it too is associated with diffuse abnormalities of large bowel epithelium. ${ }^{10}$ For example, ultrastructural studies have defined plasma membrane and other abnormalities in epithelium in apparently unaffected areas, ${ }^{11}$ studies of glycoprotein epitopes and mucin characteristics have also provided evidence for ulcerative colitis specific abnormalities, which occur independently of the presence of mucosal inflammation, ${ }^{12-16}$ and the rate of rectal epithelial proliferation is increased even in quiescent disease. ${ }^{17}$ Other studies have shown that there is enhanced expression of markers of differentiation in epithelium from inflamed regions of large bowel although these changes do not seem to be disease specific. ${ }^{18-21}$

The colonic epithelium has a higher turnover and this necessitates cells to rapidly differentiate before being shed into the lumen. There is a paucity of knowledge about factors that influence the rate of differentiation of colonic epithelial cells. We have recently evaluated the use in vitro of two markers of differentiation, the expression of brush border glycoproteins, and the rate of glycoprotein synthesis relative to that of protein synthesis, both of which show increased expression in more differentiated cells. ${ }^{22}$ Using these markers, we have shown that colonic crypt cells exhibit enhanced differentiation when serum starved ${ }^{23}$ and exposure to the physiologically relevant short chain fatty acid, butyrate, suppresses their expression in cells from macroscopically normal mucosa of cancer bearing colons. ${ }^{22}$ The last result seemed paradoxical as butyrate tends to promote differentiation of most cells in vitro but whether it reflected a normal or abnormal response was not determined.

This study aimed to define disease related responses of colonic crypt cells to short term culture and to exposure to butyrate. Specific questions considered included whether the responses to butyrate by cells from cancer bearing colons previously reported are normal or abnormal, whether colonic crypt cells from patients with ulcerative colitis exhibit abnormal responses, and whether mucosal inflammation itself influences in vitro responses. 
TABLE I Details of patient and tissue samples obtained

\begin{tabular}{|c|c|c|c|c|c|c|}
\hline \multirow[b]{2}{*}{ Patient group } & \multirow[b]{2}{*}{ No } & \multirow{2}{*}{$\begin{array}{l}\text { Age (median } \\
\text { (range) in years) }\end{array}$} & \multirow{2}{*}{$\begin{array}{l}\text { Male/ } \\
\text { female }\end{array}$} & \multicolumn{3}{|l|}{ Region* } \\
\hline & & & & Proximal & Distal & Rectum \\
\hline $\begin{array}{l}\text { Normal } \\
\text { Cancer } \\
\text { Ulcerative colitis } \\
\text { Crohn's disease }\end{array}$ & $\begin{array}{l}15 \\
24 \\
19 \\
16\end{array}$ & $\begin{array}{l}75(62-83) \\
65(35-78) \\
40(18-62) \\
28(19-61)\end{array}$ & $\begin{array}{c}4 / 11 \\
12 / 12 \\
8 / 11 \\
7 / 9\end{array}$ & $\begin{array}{c}4 \\
6 \\
19+ \\
13 \dagger\end{array}$ & $\begin{array}{c}10 \\
6 \\
4 \dagger \\
5 \dagger\end{array}$ & $\begin{array}{r}1 \\
12 \\
1 \\
0\end{array}$ \\
\hline
\end{tabular}

${ }^{\star}$ Large bowel regions: proximal = caecum/ascending colon; distal=descending/sigmoid colon; rectum $=$ rectum. + Includes paired samples.

\section{Methods}

\section{Specimens}

Large bowel mucosa was obtained from patients undergoing surgical resection because of a variety of disorders. Table I gives the patient details. The patients were divided into four groups. Firstly, 15 patients with essentially normal large bowel had resection for angiodysplasia $(n=1)$, diverticular disease (7), sigmoid volvulus (3), constipation (2), rectal prolapse (1), and one with normal large bowel who was misdiagnosed as having a caecal carcinoma on barium enema. The tissue studied (4-20 $\mathrm{cm}^{2}$ mucosal area) was macroscopically normal and adjacent mucosa was normal histologically. Secondly, macroscopically normal and uninvolved mucosa from 24 patients with colorectal cancer were studied. Results from some of these patients have been previously reported. ${ }^{9}$ Tissue was taken more than $10 \mathrm{~cm}$ from the edge of the tumour. Thirdly, mucosa was obtained from 19 patients with ulcerative colitis. The presence or absence of abnormal mucosal inflammation was determined on conventional histological criteria. Eight patients had disease that spared the proximal colon histologically both at the time of resection and on previous colonoscopic examination. Mucosa for the proximal colon was considered to be apparently normal. In four of these patients, mucosa was also obtained from an inflamed region of the colon. Six patients had mucosa studied that was previously affected but histologically inactive at the time of resection. In one of these, actively inflamed tissue was also obtained. Five patients had extensive disease and only actively inflamed mucosa was obtained. Treatment comprised moderate to high dose corticosteroids in 14 (none in five), a mesalazine delivering drug in 13, azathioprine in one, and tinidazole in one. Fourthly, 16 patients with Crohn's disease were studied. Tissue from seven patients was macroscopically normal and adjacent mucosa histologically normal; additional tissue from actively inflamed mucosa was also studied in two of those patients. Eight specimens were obtained from non-ulcerated areas of inflamed colons. Ten patients had colitis, three ileocolitis, and three ileitis. Treatment comprised moderate to high dose corticosteroids in 10 (none in two and low dose in four, a mesalazine delivering drug in seven, azathioprine in five, and metronidazole or tinidazole in four. The procurement of colonic specimens was approved by The Royal Melbourne Hospital Board of Medical Research and Ethics Committee.
Isolation of colonic crypt cells

Colonic crypt cells were isolated from resected mucosa using the collagenase/Dispase technique as previously described. ${ }^{24}$ Cell populations were contaminated with less than $8 \%$ non-epithelial cells on morphological criteria and the viability of colonic epithelial cells as assessed by $0 \cdot 1 \%$ trypan blue exclusion was always $>98 \%$. For some small specimens, insufficient cells were obtained to perform all experiments. The culture medium in which crypt viability over 24 hours in vitro has been previously shown ${ }^{22-24}$ comprised Dulbecco's modification of Eagle's medium containing $20 \%$ Nu-serum-1 (Collaborative Research, Lexington, MA, USA), $25 \mathrm{mM}$ HEPES, $4 \mathrm{mM}$ L-glutamine, 50 units/ml penicillin, $50 \mu \mathrm{g} / \mathrm{ml}$ gentamicin, and $100 \mathrm{units} / \mathrm{ml}$ nystatin. $\mathrm{Nu}$-serum is a partly defined serum substitute and contains $25 \% \mathrm{vol} / \mathrm{vol}$ newborn calf serum. A single batch of $\mathrm{Nu}$-serum was used for all experiments.

\section{Assay of alkaline phosphatase activities}

Colonic crypt cells were cultured in 96 well plates in a total volume of $0.2 \mathrm{ml}$ with or without sodium butyrate $(1 \mathrm{mM})$ in the medium. Under these conditions of culture, few cells or crypts adhere to the plastic and most remain in suspension. At the end of the culture period, the cells were harvested by aspiration from the wells followed by centrifugation and were resuspended in $1 \mathrm{ml}$ of mannitol buffer (50 $\mathrm{mM} \mathrm{D}$-mannitol and $2 \mathrm{mM}$ trizma base in $\mathrm{dH}_{2} \mathrm{O}, \mathrm{pH} \mathrm{7 \cdot 4)}$. Both the cells in buffer and supernates were stored at $-20^{\circ} \mathrm{C}$ until assayed. All studies were performed in triplicate or quadruplicate. Colonoscopic biopsy specimens were immediately placed in ice cold phosphate buffered saline, washed, and then placed in $1 \mathrm{ml}$ of mannitol buffer and stored at $-20^{\circ} \mathrm{C}$.

Just before assaying, cell suspensions or biopsy specimens were mechanically homogenised at $4^{\circ} \mathrm{C}$ in the mannitol buffer with $0 \cdot 1 \%$ Triton $\mathrm{X}-100$. Alkaline phosphatase was measured spectrophotometrically using $p$-nitrophenol as substrate ${ }^{25}$ and protein content measured using bovine gamma globulin as standard. ${ }^{26}$ Alkaline phosphatase activity was expressed relative to cellular protein content and average values for replicate samples were calculated. The coefficient of variation for alkaline phosphatase and protein estimations was $<10 \%$.

\section{Assessment of relative rate of synthesis of glycoproteins}

Colonic crypt cells were cultured in 96 well $\mathrm{U}$ bottomed plates in a total volume of $0.2 \mathrm{ml}$ in 5-6 replicate wells. As these cells cannot be accurately counted because they are anchored to each other in crypt conformation, the number of cells placed in the wells were estimated according to a visual inspection of cell pellet size after the final centrifugation step in the isolation method and varied from population to population. Retrospective analysis of DNA content per well showed this to be in the 

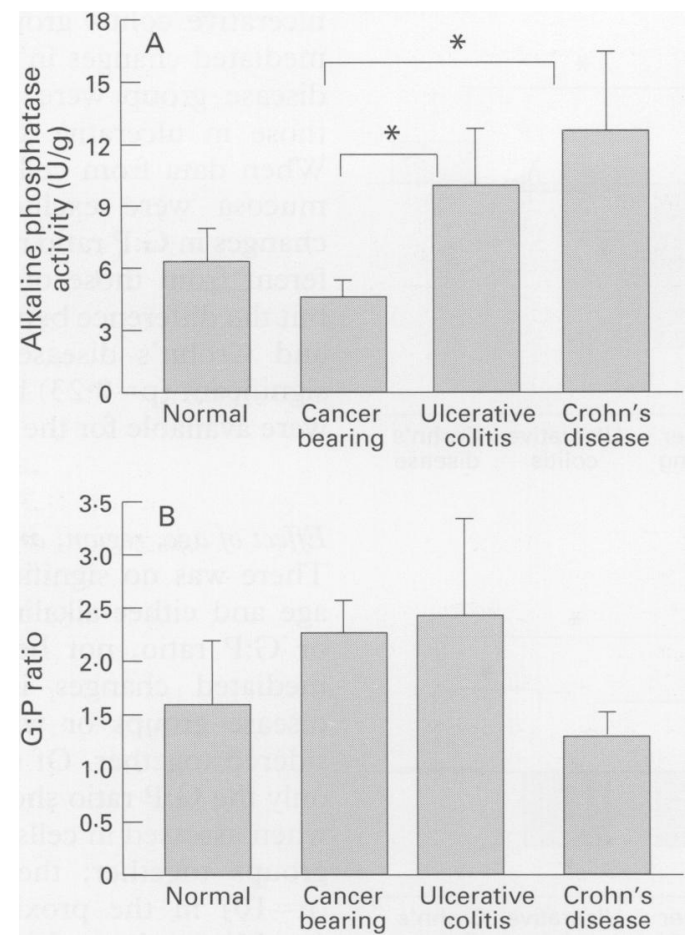

Figure 1: (A) Alkaline phosphatase activities and (B) G:P ratios across the disease groups. Results are shown as mean (SEM). Significant changes or differences are denoted by asterisks. Differences across the groups were found only for alkaline phosphatase activities $(p=0 \cdot 030$, analysis of variance); results from the cancer group were significantly. lower than those in ulcerative colitis $(p=0.004$; Student's $\mathrm{t}$ test) and Crohn's disease groups $(p=0.014)$.

range of 2-8 $\mu \mathrm{g}$. After 20-22 hours culture, the wells were pulsed for four to six hours with 1.0 $\mu \mathrm{Ci}$ of $\left[{ }^{3} \mathrm{H}\right]$-glucosamine $(20 \mu \mathrm{Ci} / \mathrm{mmol}$, $740 \mathrm{GBq} / \mathrm{mmol}$, Amersham, Little Chalfont, England) and $1.0 \mu \mathrm{Ci}\left[{ }^{14} \mathrm{C}\right]$-leucine $(0 \cdot 282$ $\mu \mathrm{Ci} / \mathrm{mmol}, 10.4 \mathrm{GBq} / \mathrm{mmol}$, Amersham). The culture was stopped by washing the cells in 1.5 ml Hanks's balanced salt solution and precipitation of protein by the addition of $1 \mathrm{ml}$ of a mixture of $10 \%$ trichloracetic acid and $1 \%$ phosphotungstic acid (TCA-PTA). The cells were washed twice in the plate and PTA-TCA added directly to the wells. Preparation of the precipitated protein pellets for beta counting then proceeded as previously described. ${ }^{22}$ Briefly, the pellets were washed three times with TCA-PTA and twice with a 1:1 mixture of chloroform and methanol. After air drying of the pellet, it was dissolved in $0.25 \mathrm{ml}$ of the tissue solubiliser, NCS (Amersham), transferred to counting tubes, and $4 \mathrm{ml}$ of nonaqueous scintillant (15 g 1,4-di[2-(5-phenyloxazolyl)] benzene and $625 \mathrm{mg} 2,5$ diphenyloxazole dissolved in 2.51 toluene with $15 \mathrm{ml}$ glacial acetic acid (added just before use) added. Radioactivity was measured in a liquid scintillation counter with double label window settings. The machine had automatic conversion to dpm after correction for quenching and isotope spill. The counts were always $>1000$ $\mathrm{dpm}$. The results were expressed as $\mathrm{dpm} / \mathrm{h}$ by dividing the counts by the number of hours of the pulse with the tracer. A glycoprotein:protein synthesis (G:P) ratio was calculated by dividing dpm for $\left[{ }^{3} \mathrm{H}\right]$-glucosamine uptake by $\mathrm{dpm}$ for $\left[{ }^{14} \mathrm{C}\right]$-leucine uptake in the same sample and the average for replicate wells determined. The coefficient of variation between replicate wells was $<15 \%$. To assess the efficiency of washing free tracer from precipitated protein, preliminary experiments were performed in which radiolabelled leucine and glucosamine were added to crypt cells and harvesting (as above) was performed within five minutes. Counts obtained in such experiments were always $<200 \mathrm{dpm}$. Previous experiments had shown that $\left[{ }^{3} \mathrm{H}\right]$-glucosamine and $\left[{ }^{14} \mathrm{C}\right]$-leucine uptake by colonic crypt cells under identical conditions was roughly constant over $>24$ hours of culture. ${ }^{22}$

\section{Statistical evaluation}

All analyses were performed using Microstat release $4 \cdot 1$ (Ecosoft Inc, Indianapolis, USA, 1984). Change in indices measured induced by butyrate was expressed as a ratio of the result in the presence to that in the absence of butyrate. Non-parametric data were expressed where appropriate by median value (range). Normally distributed data have been expressed as mean (SEM) and differences between or across groups were evaluated by analysis of variance. Paired/unpaired data were compared using the paired/Student's $t$ test (two sided). A $p$ value $\leqslant 0.05$ was considered significant.

\section{Results}

Alkaline phosphatase activities and G:P ratios under control conditions

Alkaline phosphatase activities measured at the end of 24 hours' culture in homogenates of cells from 74 patients were significantly different across the disease groups $(p=0.030)$. Figure 1 shows the results. Multiple comparisons showed alkaline phosphatase activities to be significantly lower in the cancer group than for ulcerative colitis $(p=0.004)$ and for Crohn's disease $(p=0.014)$, while activities in the normal group tended to differ only from the ulcerative colitis group $(p=0 \cdot 062)$. Results of the analysis were similar when only data obtained from cells isolated from non-inflamed mucosa in the inflammatory bowel disease patients were analysed. The alkaline phosphatase activities in freshly isolated cells, before initiation of culture, were assessed in a limited number of cell populations (five ulcerative colitis, four normal, and eight cancer) and also showed differences across the groups $(p=0.028)$. Alkaline phosphatase activities in cells from patients with ulcerative colitis $(14 \cdot 0$ $(4 \cdot 1) \mathrm{U} / \mathrm{g}$ ) was significantly higher than those from the cancer group $(4 \cdot 2 \quad(0 \cdot 7) \mathrm{U} / \mathrm{g}$; $\mathrm{p}=0.006$ ) but not significantly different from that of the normal group $(7.35(2.5) \mathrm{U} / \mathrm{g}$; $\mathrm{p}=0 \cdot 12)$.

The G:P ratio at the end of the culture period under control conditions was assessed in cells isolated from 50 patients and compared across the disease groups. Figure 1 shows the results. No significant differences across the groups were evident $(p=0.50)$ even when data from non-inflamed mucosa only were examined. 


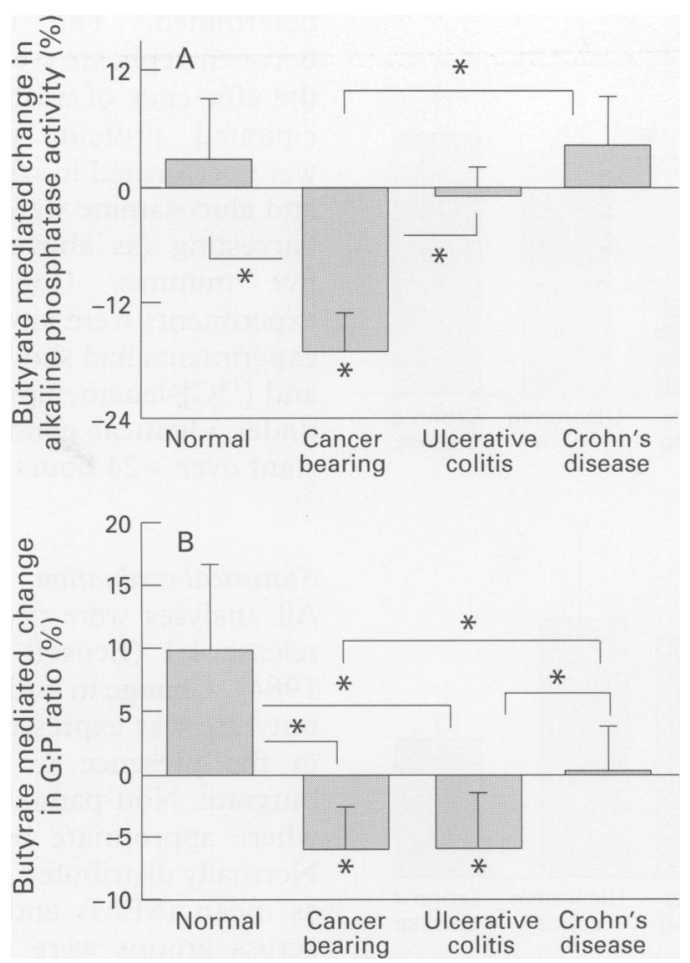

Figure 2: Butyrate mediated changes in $(A)$ alkaline phosphatase activities and (B) G:P ratios across the disease groups. Results are expressed as percentage change induced by butyrate $(1 \mathrm{mM})$ relative to the paired control and are shown as mean (SEM). Significant changes or differences are denoted by asterisks. (A) Changes in alkaline

phosphatase activities differed across the disease groups ( $p=0.003$; analysis of variance). Butyrate significantly suppressed alkaline phosphatase activities only in the cancer group ( $p=0.006$; paired t test) and these changes were significantly different from those of all other groups

$(p<0.004)$. (B) Changes in G:P ratios differed across the disease groups $(p=0.037)$. Butyrate suppressed $G: P$ ratio in cancer $(p=0.026)$ and ulcerative colitis groups

$(p=0.041)$. The changes in the cancer and ulcerative

colitis groups differed from those in the normal and Crohn's disease groups $(p<0.05)$.

Response of colonic crypt cells to 24 hour exposure to butyrate

Colonic crypt cells were exposed to butyrate at a concentration of $1 \mathrm{mM}$ and the effect on alkaline phosphatase activities was determined and compared within and across disease groups. As previously reported, ${ }^{22}$ butyrate suppressed alkaline phosphatase activities in the colorectal cancer group from $4 \cdot 1(0 \cdot 8)$ to $3 \cdot 3$ $(0.6) \mathrm{U} / \mathrm{g}(\mathrm{n}=20 ; \mathrm{p}=0.006)$. In the three other groups, however, no significant changes were seen (Fig 2). There were significant differences across the disease groups for changes in alkaline phosphatase activities $(p=0.003)$. Changes in the cancer group were significantly different to those in the other groups (all $p<0.004)$. Exclusion of data obtained in cells from inflamed mucosa did not affect the results of the analysis.

As Fig 2 shows that G:P ratios were significantly suppressed by butyrate in both colorectal cancer $(p=0.038)$ and ulcerative colitis groups $(p=0.043)$. Butyrate had no effect on G:P ratios in colonic crypt cells from normal or Crohn's disease groups. The butyrate mediated changes in G:P ratio significantly differed across disease groups $(p=0.037)$. Results from the normal group were significantly higher than those from the cancer $(p=0 \cdot 026)$ or ulcerative colitis groups $(p=0 \cdot 041)$. Butyrate mediated changes in G:P ratio in the Crohn's disease group were significantly higher than those in ulcerative colitis group $(p=0.029)$. When data from cells isolated from inflamed mucosa were excluded, butyrate mediated changes in G:P ratio remained significantly different from those of normal cells $(p=0 \cdot 045)$ but the difference between the ulcerative colitis and Crohn's disease groups was no longer significant $(p=0 \cdot 23)$ but only three data points were available for the second group.

Effect of age, region, and mucosal inflammation There was no significant correlation between age and either alkaline phosphatase activities or G:P ratio, nor between age and butyrate mediated changes in these indices within disease groups or when all cases were considered together. Of all the indices measured, only the G:P ratio showed regional differences when assessed in cells from normal and cancer groups together; the ratio was $3.03(0.51)$ $(n=10)$ in the proximal colon, $1.32(0.45)$ $(n=10)$ in those from the distal colon, and $1.66(0.24)(n=11)$ in cells from the rectum. This difference was not seen when results from the cancer group alone were analysed.

The expression of alkaline phosphatase after 24 hour culture under control conditions was similar in cells from 22 non-inflamed and 20 from inflamed mucosal specimens (Table II). The presence of mucosal inflammation also had no apparent effect on the responses of alkaline phosphatase activities and G:P ratios to butyrate. No effect of the presence or absence of mucosal inflammation was seen when results from the ulcerative colitis or Crohn's disease groups were considered separately (data not shown). In additional experiments, seven autologous pairs of cell populations were studied from areas that were either unaffected or non-inflamed, and from inflamed areas. Five of the patients had ulcerative colitis and two Crohn's disease. Alkaline phosphatase activities were $15 \cdot 0(4 \cdot 1) \mathrm{U} / \mathrm{g}$ protein from non-inflamed areas, which was similar to that from inflamed areas $(16 \cdot 1(3 \cdot 4)$ $\mathrm{U} / \mathrm{g}$ protein). Similar analysis of the effect of butyrate on alkaline phosphatase expression showed no apparent effect of mucosal inflammation $(1.02(0.03)$ versus $0.92(0.08)$, respectively). In the ulcerative colitis group, results were similar in cells from apparently normal $(n=8)$ and currently non-inflamed mucosa $(n=6)$ for both alkaline phosphatase activities $(11.2(3.5) \mathrm{U} / \mathrm{g}$ versus $8.4(4.7) \mathrm{U} / \mathrm{g} ; \mathrm{p}=0.31)$ and butyrate mediated changes $(1.02(0.03)$ versus $0.95(0.06)$, respectively; $p=0.14)$.

The effect of mucosal inflammation on the G:P ratio was assessed in 11 cell populations obtained from non-inflamed mucosa and six from inflamed mucosa. No differences were evident (Table II). Likewise, there was no difference between the effect of butyrate on G:P ratio (Table II). No differences were also seen when the ulcerative colitis group or the Crohn's disease group were analysed separately (data not shown). Though differences 
TABLE II Influence of mucosal inflammation on alkaline phosphatase activities and G:P ratios and the effect of butyrate on them in colonic crypt cells isolated from patients with inflammatory bowel disease

\begin{tabular}{lccrcc}
\hline & No & Non-inflamed & No & Inflamed & p Value $^{\star}$ \\
\hline Alkaline phosphatase (U/g) & 22 & $10.7(2 \cdot 1)$ & 20 & $11.7(2.0)$ & 0.36 \\
G:P ratio & 11 & $2.25(0.60)$ & 6 & $2.06(0.56)$ & 0.42 \\
$\Delta$ Alkaline phosphatase & 22 & $1.01(0.03)$ & 19 & $0.97(0.05)$ & 0.21 \\
$\Delta$ G:P ratiot & 11 & $0.98(0.03)$ & 6 & $0.99(0.04)$ & 0.40 \\
\hline
\end{tabular}

*Student's $t$ test. †Butyrate mediated changes expressed as a ratio of the results in the presence to absence of butyrate.

were not apparent in the response of G:P ratio to butyrate in cells from apparently unaffected mucosa of patients with ulcerative colitis $(1.00$ $(0.04)$ ) and from previously involved but currently non-inflamed mucosa (1.09 (0.03); $p=0.07)$, there were only three in each group for comparison. No autologous pairs of cells from inflamed or non-inflamed mucosa were examined.

\section{Discussion}

Sodium butyrate induces a more differentiated phenotype in many cell lines, including those derived from colon cancers. ${ }^{27}$ We have previously reported that colonic crypt cells isolated from macroscopically normal areas of cancer bearing colons behaved paradoxically when exposed to butyrate ${ }^{22}$; under identical conditions, butyrate caused considerable increases in expression of markers of differentiation in two colon cancer cell lines while the freshly isolated cells exhibited consistent suppression of the expression of the same markers. We have extended these findings in this study. Whether this effect reflects the response of truly normal colonic epithelium to butyrate and, if not, whether butyrate induces differentiation as it does for cell lines were important issues to be considered. Fifteen cell populations isolated from mucosa resected because of non-neoplastic, non-inflammatory conditions provided the basis for considering normal responses. The cells exhibited similar alkaline phosphatase activities and G:P ratios under control conditions to those in the cancer group. Butyrate had no consistent or significant effect on either parameter, however, and the responses were significantly different from those in the cells from cancer bearing colons. Thus, butyrate has no discernible effect on markers of differentiation in normal colonic crypt cells in vitro and butyrate mediated effects previously seen for 'normal' cells from cancer bearing colons are indeed abnormal.

It is curious that three types of response to butyrate are seen under the same conditions: accelerated differentiation in colon cancer cell lines, no response in normal crypt cells, and suppression in cells from cancer bearing colon. The differences probably do not reflect differences in cell viability. There is little doubt that most cells, irrespective of the underlying disease, remain viable over the period of study as they continued to incorporate glucosamine and leucine into glycoproteins and proteins respectively. Under similar conditions, the cells continue to synthesise and secrete interleukin $8,{ }^{28}$ urokinase, and plasminogen activator inhibitor 1,29 and cellular alkaline phosphatase increases over the 24 hour culture period. ${ }^{23}$ Evidence from our laboratory suggests that colonic crypt cells differentiate constitutively after their isolation; alkaline phosphatase activities increase with time and, with serum deprivation, both alkaline phosphatase activities and G:P ratios exhibit a further significant increase compared with cells exposed to serum despite a general decrease in protein synthetic activity. ${ }^{23}$ It might be that removal of the suppressive factors in serum allows intrinsically determined pathways of differentiation to be followed, a process not unlike that recently postulated for the action of colony stimulating factors on lymphoid cells. ${ }^{30}$ This cell system may, therefore, represent one already exhibiting accelerated differentiation under control conditions. This is in contrast with the situation for colon cancer cells, which usually exhibit only low levels of differentiation when unstimulated by extrinsic factors. In other words, butyrate responsiveness may depend on either the degree of differentiation (advanced for normal cells) or commitment to differentiation (strong for normal cells). Butyrate also seems capable of suppressing pathways of differentiation of colonic crypt cells but why this manifests only in cells from cancer bearing colons is uncertain.

Evidence that diffuse epithelial abnormalities are present in colorectal neoplasia is strong; abnormal findings, such as increased rate of proliferation, ${ }^{3-6}$ abnormal morphology, ${ }^{78}$ and abnormal mucosal brush border hydrolase expression, ${ }^{9}$ are found in vivo, and responses to butyrate, such as an enhanced suppressive effect of butyrate on urokinase secretion and a blunted stimulatory effect on plasminogen activator inhibitor 1 secretion, ${ }^{31}$ are present in vitro. Now abnormal butyrate mediated effects on markers of differentiation can be added to the list. The biological basis for such responses to butyrate is poorly understood.

Abnormal patterns of results were also seen for cells from ulcerative colitis patients. Butyrate suppressed G:P ratio and this response was significantly different from that in the normal group. This effect was disease specific as the response to butyrate in the Crohn's disease group was normal and also differed significantly from that in the ulcerative colitis group. The abnormal response seen does not simply mimic that seen for cells from the cancer group - alkaline phosphatase activities were unaffected by butyrate - and, therefore, is less easily explained by a butyrate mediated suppression of pathways of differentiation.

The biological significance of small changes in G:P ratio is uncertain but it is possible that a $5 \%$ reduction in glycosylation of proteins may have considerable effect on functional properties of the resultant glycoproteins or that this small overall change might reflect appreciable changes in a few specific glycoproteins. Butyrate exposure to colonic crypt cells does diminish during culture caused by its consumption by the cells (unpublished data) and it 
is possible that greater effects may have been seen if butyrate concentrations in the medium were maintained at comparatively high values. Our previous studies in cells from cancer bearing colons showed a concentration dependent effect of butyrate on G:P ratio but the magnitude of the change induced was still numerically small. ${ }^{22}$ Other effects of butyrate on crypt cells under the same conditions, such as reduction of steady state transcript values for interleukin 8 and urokinase in addition to the respective protein products, ${ }^{28} 31$ are maintained for at least 18 hours. Whether cellular butyrate oxidation differs across disease groups under the conditions of culture has not been investigated. Short term metabolic studies of different colonic epithelial populations under different conditions have shown reduced ${ }^{32}$ or normal ${ }^{33}$ oxidation of butyrate by cells from patients with ulcerative colitis. ${ }^{32}$ Whether the comparative 'energy deficiency' postulated to occur in the cells in this disease, ${ }^{32}$ or perhaps - differing intracellular values of butyrate resulting from lack of its disposal, are responsible for this pattern of responses requires further investigation.

Though most cell populations were obtained from proximal colon and the patients were generally of a younger age in the ulcerative colitis compared with normal and cancer groups, none of these variables could be implicated as artefactually causing the differences. Likewise, mucosal inflammation had no apparent influence on the results and the antiinflammatory or immunosuppressive treatment, or both most patients were receiving was also a constant feature in the Crohn's disease patients. In other words, this perturbation of colonic epithelium in ulcerative colitis is diffuse, disease specific, and independent of the presence of mucosal inflammation. Other abnormalities sharing these features have been reported and include abnormalities in mucin characteristics, ${ }^{12-14}$ glycoprotein epitope expression, ${ }^{15} 16$ and morphological features. ${ }^{11}$ The basis for such abnormalities are not defined although a twin study has shown some mucin abnormalities to be genetically determined. ${ }^{13}$ Whatever the mechanism, the presence of such epithelial abnormalities independently of the presence of mucosal inflammation supports the hypothesis that abnormalities of colonic epithelium are early events in the pathogenesis of ulcerative colitis.

The biological significance of the findings made in this study, apart from highlighting diffuse epithelial abnormalities in ulcerative colitis and colorectal cancer, is unclear. A key finding in both diseases in the increased rate of proliferation of colonic epithelial cells. $^{3-6} 17$ 34-36 An important event that controls proliferation of hierarchal cells like colonic epithelium is the rate of cell death. Apoptosis occurs as the final stage in the differentiation of keratinocytes. ${ }^{37}$ If apoptosis and differentiation are processes in the same pathway in colonic epithelium, and in situ labelling of DNA fragmentation would suggest it is so, ${ }^{38}$ acceleration of the differentiation process suggested by the in vitro findings of this study might be associated with accelerated cell death and subsequent increase in the rate cell proliferation. Defining the molecular basis for such abnormality might therefore, provide important clues to pathogenic events in ulcerative colitis and in colorectal tumorigenesis.

In conclusion, 24 hour exposure of normal colonic crypt cells to butyrate in vitro has no effect on their expression of markers of differentiation. The previously described butyrate mediated suppression of differentiation in colonic crypt cells from cancer bearing colons is, therefore, an abnormal response. An inflammation independent, disease specific abnormality of the response of G:P ratio to butyrate was seen in colonic crypt cells from patients with ulcerative colitis. These results provide further evidence for diffuse but differing abnormalities of colonic epithelium in both ulcerative colitis and colorectal carcinoma.

These data were published in part in abstract form in Gastroenterology 1994; 106: A687.

1 Wilson JKV. Biology of large bowel cancer. Dermatol Oncol Clin North Am 1989; 3: 19-34.

2 Fearon ER, Vogelstein B. A genetic model for colorecta tumorigenesis. Cell 1990; 61: 759-67.

3 Deschner EE, Lipkin M. Proliferative patterns in colonic mucosa in familial polyposis. Cancer $1975 ; 35: 413-8$.

4 Terpstra OT, Van Blankenstein M, Dees J, Eilers GAM. Abnormal pattern of cell proliferation in the entire colonic mucosa of patients with colon adenoma or cancer. Gastroenterology 1987; 93: 704-8.

5 Pons de Leon M, Roncucci L, DiDonato P, Tassi L Smerieri O, Amorico MG, et al. Pattern of epithelial cell proliferation in colorectal mucosa of normal subjects and proliferation in colorectal mucosa of normal subjects and of patients with adenomatous polyps or
bowel. Cancer Res 1988; 48: 4121-6.

6 Wilson RG, Smith AN, Bird CC. Immunohistochemical detection of abnormal cell proliferation in colonic mucosa of subjects with polyps. $\mathcal{f}$ Clin Pathol 1990; 43: 744-7.

7 Lee YS. Background mucosal changes in colorectal carcinomas. Cancer 1988; 61: 1563-70.

8 Shamsuddin AKM, Weiss K, Phelps PC, Trump BF. Colon epithelium. Human colon carcinogenesis. Changes in human colon mucosa adjacent to and remote from carcinomas of the colon. $\mathcal{F}$ Natl Cancer Inst 1981; 66: 413-9.

9 Gibson PR, Folino M, Rosella O, Finch CF, Moeller I, Alexeyeff $\mathrm{M}$, et al. Neoplasia and hyperplasia of the large bowel - focal lesions in an abnormal epithelium. bowel - focal lesions in an abint
Gastroenterology 1992; 103: 1452-9.

10 Gibson PR, Pavli P. Pathogenic factors in inflammatory bowel disease. I. Ulcerative colitis. Dig Dis 1992; 10 $17-28$.

11 Delpre G, Avidor I, Steinherz R, Kadish U, Ben-Bassat M Ultrastructural abnormalities in endoscopically and histologically normal and involved colon in ulcerative colitis. Am $\mathcal{f}$ Gastroenterol 1989; 84: 1038-46.

12 Podolsky DK, Isselbacher KJ. Glycoprotein composition of colonic mucosa: specific alterations in ulcerative colitis. Gastroenterology 1984; 87: 991-8.

13 Tysk C, Riedesel H, Lindberg E, Panzini B, Podolsky D, Jarnerot G. Colonic glycoproteins in monozygotic twins
with inflammatory bowel disease. Gastroenterology 1991; 100: 419-23.

14 Morita H, Kettlewell MG, Jewell DP, Kent PW. Glycosylation and sulphation of colonic mucus glycoproteins in patients with ulcerative colitis and in healthy subjects. Gut 1993; 34: 926-32.

15 Podolsky DK, Fournier DA. Emergence of antigenic glycoprotein structures in ulcerative colitis detected through monoclonal antibodies. Gastroenterology 1988; 95: 371-8.

16 Podolsky DK, Fournier DA. Alterations in mucosal content of colonic glycoconjugates in inflammatory bowel disease defined by monoclonal antibodies. Gastroenterology 1988; 95: 379-81.

17 Allan A, Bristol JB, Williamson RCN. Crypt cell production rate in ulcerative proctocolitis: differential increments in rate in ulcerative proctocolitis: differential incre

18 Haviland AE, Borowitz MJ, Lan MS, Kaufman B Khorrami A, Phelps PC, et al. Aberrant expression of monoclonal antibody-defined colonic mucosal antigens in inflammatory bowel disease. Gastroenterology 1988; 95: 1302-11

19 Wolf BC, D'Emilia JC, Salem RR, DeCoste D, Sears HF Gottlieb LS, et al. Detection of the tumour-associated glycoprotein antigen (TAG-72) in premalignant lesions of the colon. $\mathcal{F}$ Natl Cancer Inst 1989; 81: 1913-7.

20 Cooper HS, Steplewski Z. Immunohistologic study of ulcerative colitis with monoclonal antibodies against tumorassociated and/or differentiation antigens. Gastroenterology 1989; 95: 686-93. 
21 Greenstein AJ, Panvelliwalla DK, Katz LB, Heimann TM, Donnelly J, Pertsimlidis D, et al. Tissue carcinoembryonic antigen, dysplasia, and disease duration in colonic inflammatory bowel disease. Am $\mathcal{F}$ Gastroenterol 1982; 77: $212-5$.

22 Gibson PR, Moeller I, Kagelari O, Folino M, Young GP. Contrasting effects of butyrate on the expression of phenotypic markers of differentiation in neoplastic and phenotypic markers of differentiation in neoplastic and non-neoplastic colonic epithelial

23 Gibson PR, Rosella O, Young GP. Serum-free medium increases expression of markers of differentiation in human colonic crypt cells. Gut 1994; 35: 791-7.

24 Gibson PR, van de Pol E, Maxwell LE, Gabriel A, Doe WF Isolation of colonic crypts that maintain structural and metabolic viability in vitro. Gastroenterology 1989; 96: 283-91

25 Young GP, Rose IS, Cropper S, Seetharam S, Alpers DH. Hepatic clearance of rat plasma intestinal alkaline phosphatase. Am 7 Physiol 1984; 247: G419-26.

26 Bradford $M$. A rapid and sensitive method for the quantitation of microgram quantities of protein utilizing the principle of protein-dye binding. Anal Biochem 1976;72: ciple of

27 Young GP, Gibson PR. Contrasting effects of butyrate on proliferation and differentiation of normal and neoplastic cells. In: Rombeau JL, Cummings JH, Sakata T, ed Short-chain fatty acids: metabolism and clinical importance. Columbus, Ohio: Ross Laboratories, 1991: 50-5.

28 Gibson PR, Rosella O. Interleukin-8 secretion by colonic crypt cells in vitro: modulation and disease differences. Gastroenterology 1994; 106: A687.

29 Gibson PR, Rosella O, Rosella G, Young GP. Secretion of urokinase and plasminogen activator inhibitor-1 by normal colonic epithelium in vitro. Gut 1994; 35: 969-75.

30 Fairbairn LJ, Cowling GJ, Reipert BM, Dexter TM. Suppression of apoptosis allows differentiation and development of a multipotent hemopoietic cell line in the absence of added growth factors. Cell 1993; 74: the absence

31 Gibson PR, Rosella O, Rosella G, Young GP. Butyrate is a potent inhibitor of urokinase secretion by normal colonic
epithelium in vitro. Gastroenterology 1994; 107: 410-9.

epithelium in vitro. Gastroenterology 1994; 107: 410-9.
32 Finnie IA, Taylor BA, Rhodes JN. Ileal and colonic epithelial metabolism in quiescent ulcerative colitis: increased glutamine metabolism in distal colon but no defect in butyrate metabolism. Gut 1993; 34: 1552-8.

33 Roediger WEW. The starved colon - diminished mucosa nutrition, diminished absorption, and colitis. Dis Colon Rectum 1990; 33: 858-62.

34 Bleiberg H, Mainguet P, Galand P, Chreien J, DupontMairesse N. Cell renewal in the human rectum. In vivo autoradiographic study on active ulcerative colitis. Gastroenterology 1970; 58: 851-5.

35 Eastwood GL, Trier JS. Epithelial cell renewal in cultured rectal biopsies in ulcerative colitis. Gastroenterology 1973; rectal biopsies $383-90$.

36 Serafini EP, Kirk AP, Chambers TJ. Rate and pattern of epithelial cell proliferation in ulcerative colitis. Gut 1981; 22: 648-52

37 McCall CA, Cohen JJ. Programmed cell death in terminally differentiating keratinocytes: role of endogenous endonuclease. F Invest Dermatol 1991; 97: 111-4.

38 Gavrieli Y, Sherman Y, Ben-Sasson SA. Identification of programmed cell death in situ by specific labelling of nuclear DNA fragmentation. $f$ Cell Biol 1992; 119: 493-501. 